\title{
滇南热带季雨林的一些问题讨论
}

\author{
朱 华 \\ (中国科学院西双版纳热带植物园昆明分部, 昆明 650223)
}

\begin{abstract}
摘 要 通过分析云南南部的水、热条件及植被分布, 讨论了季雨林植被类型及其特征, 认为云南南部的季雨林是 介于热带雨林与萨王纳之间的, 在干季基本上是落叶的一种森林植被类型, 符合 Schimper (1903)定义的热带季雨林 植被, 并考虑它是一种生态学意义上的经向地带性植被, 与该地区的纬向地带性植被热带季节雨林一起共同构成 云南南部的水平地带性植被。在云南南部的石灰岩山坡分布的过去被认为是季雨林的森林植被, 尽管也受到季节 性干旱的影响而不同程度地具有落叶成分, 但它在群落外貌上与典型的季雨林不相同, 在植物区系组成上也明显 不同于该地区非石灰岩山地的季风常绿阔叶林, 在分布上亦是在石灰岩低山沟谷的热带季节性雨林水平地带性植 被带之上, 根据其生态外貌、植物区系组成和生境特点, 我们建议用“热带季节性湿润林”来称呼这类石灰岩山地森 林类型, 在性质上属东南亚热带北缘石灰岩山地垂直带上的一种植被类型。
\end{abstract}

关键词 热带季雨林 季节性湿润林 云南南部

\section{RECLASSIFICTION OF MONSOON TROPICAL FORESTS IN SOUTHERN YUNNAN, SW CHINA}

\author{
ZHU Hua \\ (Xishuangbanna Tropical Botanical Garden, Chinese Academy of Sciences, Kunming 650223, China)
}

\begin{abstract}
Southern Yunnan is located biogeographically at a transitional zone between tropical Southeast (SE) Asia and subtropical East Asia, and though far north of the Equator and at a relatively high altitude, has a rich and diverse tropical flora. The terminology used to describe the different tropical forest types in the region are confusing because the classification schemes used come from different disciplines. Using the classification scheme of tropical plant formations by Schimper (1903) and Richards (1996), which is based primarily on climatic factors, we discuss a new classification scheme of the tropical forests in southern Yunnan. Horizontal vegetation types in southern Yunnan are represented by tropical seasonal rain forests and monsoon forests. The tropical seasonal rain forest is a tropical Asian rain forest at altitudinal and latitudinal limits, while the monsoon forest is considered to be a transitional vegetation type between tropical rain forests and savannas based on their physiognomy and distribution. The monsoon forest is largely leafless during the dry season. The forests that occur on the middle and upper limestone slopes in southern Yunnan, which was called a monsoon forest in some Chinese botanical references, is reclassified as a seasonal moist forest. These forests are not equivalent to classical monsoon forests in their physiognomy, despite of the fact that it is affected by seasonal dryness and contains a high percentage of deciduous trees. The floristic composition also is different from monsoon evergreen broad-leaved forests in the region. This limestone forest, which abuts the seasonal rain forest on lower slopes and in the limestone valleys, is an altitudinal vegetation type on limestone bedrock in southern Yunnan.
\end{abstract}

Key words Monsoon forest, Seasonal moist forest, Southern Yunnan

云南南部地处大陆东南亚热带北缘山地, 具有 山原地貌和季风气候特点, 与东南亚热带森林分布 的主要地区相比, 热量偏低, 降雨偏少, 日温差大。 由于该地区特殊的地形地貌, 其北、西面的中高山, 在一定程度上阻挡了西北方来的冷气流, 使得在其 河谷、低山地区最冷月均温并不低 (为 $15.2{ }^{\circ} \mathrm{C}$ ), 其 低山沟谷及低丘上, 冬季 (干季)有浓雾, 这又在一定
程度上为地面起保暖作用, 减小了低温对森林植被 的影响, 因而在该地区的低山沟谷及低丘上, 形成 热带气候, 具有热带森林发育。由于局部地形的气 候分异, 干季的浓雾 (日雾露水量平均 $0.1 \sim 0.3$ $\mathrm{mm}$, 最高 $1 \mathrm{~mm}$ ) 也在一定程度上弥补了降水的不 足, 在该地区的低山沟谷及低丘上, 局部仍能形成 热带湿润气候, 又具有热带雨林发育。该地区的热 
带雨林不仅与山地常绿阔叶林, 而且与低山和低丘 上的一些半常绿和落叶的热带森林植被形成镶嵌交 错的分布格局。

云南南部的热带雨林发育在东南亚季风热带北 缘山地, 它在群落外貌上有明显的季节变化(有一定 比例的落叶树种存在), 其区系成分又具有热带北部 边缘和过渡性质, 与东南亚赤道地区的热带雨林有 一定差异, 并表现为一种在水分、热量和海拔分布上 均到了极限条件的热带雨林类型, 被称为热带季节 雨林(曲仲湘等, 1960; 吴征镒, 1980, 1987; 金振洲, 1983, 朱华等, 1998; Zhu，1997）。然而, 该地区与热 带季节雨林交错分布的其它一些常绿、半常绿和落 叶的热带森林植被, 则在名称叫法上有混淆。

吴征镒 $(1980,1987)$ 主要考虑到云南南部位于 季风热带北缘这一地理特点, 把云南南部与热带季 节雨林交错分布的一些常绿和半常绿的热带森林植 被, 同中国其它热带北缘地区的类似植被一道, 称 为热带季雨林, 认为它们是分布于热带北缘的一个 植被类型, 它们一方面向雨林方向发展, 同时也有 向亚热带常绿润叶林过渡的特点。也就是说, 它们 是一个介于热带雨林和亚热带常绿润叶林之间的植 被类型, 属于纬向地带性植被。

王伯称 (1987), 林媚珍等 (1996), 王伯蒜和张炜 银 (2002) 提出了不同的看法, 他们根据 Schimper (1903) 最初建立的季雨林 (Monsoon forest) 的概念和 定义, 以及国外有关学者对该名称的运用（Beard, 1944, 1955; Whittaker, 1970), 就像 Schimper 的原始 定义那样, 认为季雨林是一种在干季基本上是无叶 的、界于雨林与稀树草原(萨王纳)之间的植被类型， 属于经向地带性植被, 并依此定义, 通过对广东和 海南的季雨林特点的分析, 认为《中国植被》对热带 季雨林的解释和运用是不对的。

居于此争论, 我们拟通过对云南南部的与热带 季节雨林交错分布的过去被称作季雨林的这类热带 森林植被及其特征分析，对这些问题进行探讨。

\section{1 云南南部的气候特点及其地带性植被类} 型

云南南部基本上以山原为主, 其中分布着河谷 盆地、低山和低丘, 河谷盆地的平均海拔都在 $550 \mathrm{~m}$ 以上。在海拔 $900 \sim 1000 \mathrm{~m}$ 以下的低山、低丘及河 谷盆地, 是热带气候区。以预腊县 (海拔 $631.9 \mathrm{~m}$ ) 为例: 年均温 $21{ }^{\circ} \mathrm{C},>10{ }^{\circ} \mathrm{C}$ 积温 $7639{ }^{\circ} \mathrm{C}$, 最热月 均温 $24.6{ }^{\circ} \mathrm{C}$, 最冷月均温 $15.2{ }^{\circ} \mathrm{C}$; 年降雨量 1531.9 $\mathrm{mm}$, 干季 (11) 翌年 4 月)降雨 $282 \mathrm{~mm}$, 湿季 (5 10 月)降雨 $1250 \mathrm{~mm}$, 相对湿度 $80 \%$ 。年温差小, 日 温差大,干湿季变化十分明显。在该地区的热带气 候区域, 年降雨量随不同局部地形而变化, 可从 1200 到 $1600 \mathrm{~mm}$ 。

热带雨林可以发育在年平均温度 $20^{\circ} \mathrm{C}$ 以上的 地区 (Richards, 1996), 云南南部海拔 $900 \sim 1000 \mathrm{~m}$ 以下的区域, 虽已处在热带雨林发育的年平均温度 下限, 但仍在热带雨林分布的热量范围。在水分因 子上, Richards (1996)根据年降雨量和年干旱月数把 热带低地森林分布地区的气候分为: 1 ) 热带极潮湿 （Tropical super wet, 年降雨量 $\geqslant 3000 \mathrm{~mm}$, 年干旱月 数为 0 )；2) 热带潮湿 (Tropical wet, 年降雨量 $\geqslant 2000$ $\mathrm{mm}$, 年干旱月数为 $0 \sim 3$ ); 3 ) 热带季节性潮湿 （Tropical wet-seasonal, 年降雨量 $\geqslant 1700 \mathrm{~mm}$, 年干旱 月数为 $3 \sim 5$ ); 4) 热带湿润 (Tropical wet-dry marked by dry season, 年降雨量 $\geqslant 1200 \mathrm{~mm}$, 年干旱月数为 4 6)；5)热带半湿润 (Tropical wet-dry with long-dry sea$\mathrm{son}$, 年降雨量 $\geqslant 700 \mathrm{~mm}$, 年干旱月数为 $6 \sim 8$ ); 6) 热 带半干旱( Tropical semi-arid, 年降雨量 $<700 \mathrm{~mm}$, 年 干旱月数 $>8$ )。与之相对应的植被类型是: 热带极 潮湿和热带潮湿气候——低地湿润雨林 (Lowland rain forest), 热带季节性潮湿气候——常绿季节林 (Evergreen seasonal forest), 热带湿润气候——半常绿 季节林 (Semi-evergreen seasonal forest), 热带半湿润气 候一一落叶季节林 (Deciduous seasonal forest), 热带 半干旱气候——多刺林 (Thorn forest)。这与 Schimper（1903）对热带森林植被类型的划分类似，其落 叶季节林相当于 Schimper 的季雨林 (Monsoon forest), 多刺林相当于 Schimper 的萨王纳植被 (Savanna）。二者均把热带季雨林或热带落叶季节林作为 与热带雨林有同样的热量要求, 但水湿因子不同, 介 于热带雨林与萨王纳之间的植被类型, 属于经向地 带性植被。

按 Richards(1996) 的分类, 云南南部的气候应是 介于热带湿润和热带半湿润气候区之间, 在此气候 下发育的地带性植被理论上是半常绿季节林和落叶 季节林。然而, 由于该地区的特殊地形地貌, 干季的 浓雾及局部地形下的湿润土壤在一定程度上弥补了 降水的不足，在局部仍能形成较地区性气候更为湿 润的小气候, 这些局部生境的半常绿季节林落叶成 分相对较少, 雨林特征发育, 成为低地热带雨林的 一个类型一一热带季节雨林。而在较开阔的盆地和 受季风影响强烈的河谷, 发育有落叶季节林, 即 
Schimper (1903) 定义的季雨林。因此, 云南南部的 热带季节雨林和季雨林是该地区的水平地带性植 被。这类热带季节雨林是东南亚热带雨林的北缘类 型, 由于南低北高的地势, 它既具有向亚热带常绿阔 叶林过渡, 又有向热带山地的常绿阔叶林过渡的特 点, 仍属于纬向地带性植被。该地区的季雨林, 与热 带季节雨林水平交错分布和与热带山地的常绿阔叶 林过渡, 发育主要受水分因子控制, 符合于 Schimper (1903) 定义的与热带雨林有同样的热量要求, 但水 湿因子不同, 介于热带雨林与萨王纳之间的被 Schimper 划归为经向地带性的植被类型。滇南的季 雨林经向地带性分布特征不典型, 但考虑到与该地 区纬向地带性植被季节雨林的关系, 仍可认为它是 一种生态学意义上的经向地带性植被, 与纬向地带 性植被季节雨林一起共同构成该地区的水平地带性 植被。

\section{2 热带季雨林}

按 Schimper（1903) 的定义, 季雨林是在具有明 显干、湿季变化的热带季风气候下发育的介于热带 雨林与萨王纳之间的一种热带落叶森林植被。在云 南南部, 季雨林的形成主要受水分因素控制, 主要 分布在海拔 $900 \mathrm{~m}$ 以下的澜沧江开阔河段两岸和一 些开阔河谷盆地受季风影响最强的地段。这类季雨 林群落高度较矮,一般高 $25 \mathrm{~m}$ 以下, 结构相对简单, 乔木一般仅有一至二层, 上层树种在干季落叶或上 层及下层树种在干季都落叶, 即有一个明显的无叶 时期。上层树种树冠通常呈伞状, 冠幅大, 分枝低, 枝桠粗大弯曲, 树皮厚而粗䊁, 也有板根现象, 但林 内明显较干燥, 木质藤本及大型附生植物少。这些 特征与 Schimper 定义的季雨林符合。

云南南部的季雨林代表树种有木棉 ( Bombax $c e i b a$ )、毛麻栋 (Chukrasia tabularis var. velutina)、劲 直刺桐 (Erythrina stricta), 东京枫扬 (Pterocarya tonkinensis)、楹树 ( Albizia chinensis)、桂火绳 (Eriolaena kwangsiensis)、钝叶黄檀( Dalbergia obtusifolia)、居间紫 薇( Lagerstroemia intermedia)、余甘子( Phyllanthus emblica)、羊蹄甲(Bauhinia variaegata)、榆绿木( Anogeissus acumunata)、一担柴(Colona floribunda)、槟榄青( Spondias pinnata)、火烧花 (Mayodendron igneum) 帽柱 木( Mitragyna brunonis)等。季雨林在一些局部地段 上常形成单优群落, 如木棉林 (李保贵等, 1993)、榆 绿木林(王洪和朱华, 1990)、东京枫扬林(李保贵等, 1999)等。

\section{3 热带季节性湿润林}

在云南南部的石灰岩山中部地带, 分布有一类 特殊的森林植被类型, 这类森林群落高度通常为 20 $\sim 25 \mathrm{~m}$, 在局部地方部分落叶大树也可高达 $30 \mathrm{~m}$, 乔 木层通常具有两个清楚的层次, 在土壤较丰富而湿 润的地段, 群落中乔木 $\mathrm{B}$ 层以下有时还可见由上层 乔木的瘦弱小树组成一个高约 $2 \sim 3 \mathrm{~m}$ 的矮林层, 林 内木质藤本丰富, 厚叶的维管附生植物普遍。由于 石灰岩山坡中部的地型和生境变化最大, 至使此类 森林在外貌和区系成分的组成上差异明显。该森林 类型在阴坡、低丘顶部和较高的山丘上部呈常绿季 相, 在较为宽阔而干燥的河谷和中低山丘的干燥阳 坡则呈半常绿季相。这种森林类型在我国的植物学 文献资料中曾被称之为石灰岩山“季雨林” (吴征 钑, 1987)。尽管此类森林受到季节性干旱的明显 影响而不同程度地具有落叶成分, 但它在许多方面 与 Schimper (1903) 的季雨林不相同, 它们是一种基 本上常绿或半常绿的森林群落, 一些树木的落叶发 生在旱季末期, 有的甚至在雨季落叶, 有的树木在老 叶落地的同时又在生长新叶。也就是说, 这类森林 的乔木层并没有一个明显的无叶 (落叶) 期, 这类森 林的落叶特征可能主要是由于生境的干燥和历史的 原因造成的。如果我们采纳 Schimper (1903) 的季雨 林概念, 则滇南石灰岩山地的这类森林植被就不宜 称为季雨林, 因为 Schimper 定义的季雨林是一种在 干季基本上是无叶的、界于雨林与稀树草原 (萨王 纳)之间的植被类型。

滇南的这类森林通常分布在石灰岩山中部, 并 在石灰岩山脚及沟谷的季节性雨林带之上, 它们应 是该地区山地垂直带上的一种植被类型。该地区非 石灰岩山地季节性雨林带之上主要分布着以茶科、 樟科和壳斗科植物为乔木优势成分的热带山地常绿 阔叶林或称季风常绿阔叶林的森林植被, 而与之对 应的分布在石灰岩山地的这类森林以大戟科植物, 如尖叶闭花木 (Cleistanthus sumatranus)、石山巴豆 (Croton crassifolius)、缅桐 ( Sumbaviopsis albicans)、轮 叶戟 (Lasiococca comberi var. pseudoverticillata) 等; 榆 科植物, 如油朴 (Celtis philippensis var. wightii); 木 犀科植物, 如多脉桂花 (Osmanthus polyneurus); 龙舌 兰科植物, 如岩棕 (Dracaena cochinchinensis) 等占优 势。它们在群落外貌上不同于季雨林, 在植物区系 组成上不同于季风常绿阔叶林, 在分布上发育在热 带季节性雨林带之上的石灰岩山地, 根据其生态外 
貌、植物区系组成和生境特点, 我们建议用“热带季 节性湿润林 (Tropical seasonal moist forest)” 来称呼这 类常绿或半常绿的石灰岩山地森林类型 (Zhu et al., 1998, 2003; Zhu, 2002), 它们属东南亚热带北 缘石灰岩山地垂直带上的一种植被类型。

根据我们对云南南部的石灰岩山地植被的研究 (Zhu et al., 1998, 2003; Zhu，2002), 过去我国植物 学文献资料中所描述的云南南部的石灰岩山“季雨 林”, 实际上包含了石灰岩低山沟谷的热带季节性雨 林和本文所建议的石灰岩山地的热带季节性湿润林 两个不同的植被类型。石灰岩山地的热带季节性湿 润林在群落外貌上不同于季雨林和热带雨林, 在植 物区系组成上不同于季风常绿阔叶林, 我们建议在 云南植被分类系统中把它作为一个单独的植被型。

\section{4 结 论}

云南南部虽位于东南亚热带北缘, 受热带季风 气候控制, 由于该地区的特殊地形地貌, 其北、西面 的中高山, 在一定程度上阻挡了西北方来的冷气流, 其低山沟谷及低丘上, 冬季 (干季) 有浓雾, 这又在一 定程度上对地面有保暖作用, 减小了低温对森林植 被的影响,干季的浓雾及局部地形下的湿润的土壤 也在一定程度上弥补了降水的不足, 在局部仍能形 成较地区性气候更为湿热的小气候, 具有热带雨林 植被发育, 但这种热带雨林与东南亚赤道地区的热 带雨林有一定差异, 表现为一种在水分、热量和海拔 分布上均到了极限条件的热带雨林类型, 被称为热 带季节雨林。在该地区较开阔的盆地和受季风影响 强烈的河谷, 发育有在干季基本上是落叶的森林植 被, 与 Schimper (1903) 定义的季雨林相符。因此, 云南南部的热带季节雨林和季雨林是该地区的水平 地带性植被。这类热带季节雨林是东南亚热带雨林 的北缘类型, 它既具有向亚热带常绿阔叶林过渡, 又 有向热带山地的常绿阔叶林过渡的特点, 仍属于纬 向地带性植被。但该地区的季雨林与季节雨林水平 交错分布, 与热带山地的常绿阔叶林过渡, 发育主要 受水分因子控制, 符合于 Schimper (1903) 定义的与 热带雨林有同样的热量要求, 但水湿因子不同, 介于 热带雨林与萨王纳之间的季雨林植被类型。由于 Schimper 把季雨林划归经向地带性植被, 尽管滇南 的季雨林经向地带性分布特征不典型，但考虑到与 该地区纬向地带性植被季节雨林的关系, 我们认为 仍将其划归经向地带性植被为宜。

在云南南部的石灰岩山地分布的基本上是常绿
或半常绿的森林植被, 在我国的植物学文献资料中 曾被称为石灰岩山“季雨林”, 但它们在群落外貌上 与 Schimper 定义的季雨林不相同, 在植物区系组成 上也明显不同于该地区非石灰岩山地的热带山地常 绿阔叶林或称季风常绿阔叶林, 在分布上亦是在石 灰岩低山沟谷的热带季节性雨林水平地带性植被带 之上,我们建议用“热带季节性湿润林”来称呼这类 石灰岩山地森林类型, 它们属东南亚热带北缘石灰 岩山地垂直带上的一种植被类型。

在云南南部,“季雨林”应仅应用于那些在干旱 季节或多或少落叶的在生态上介于热带雨林与萨王 纳之间的热带森林植被类型。

\section{参 考 文 献}

Beard JS (1944). Climax vegetation in tropical America. Ecology, $25,127-158$

Beard JS (1955). The classification of tropical American vegetation types. Ecology, 36, 359-412.

Jin ZZ (金振洲) (1983). The characteristics of tropical rain forest and monsoonal forest in Yunnan. Journal of Yunnan University (云南大学学报), $1 \&$ 2, 197 - 205. (in Chinese with English abstract)

Li BG. (李保贵), Zhu H (朱华), Wang H (王洪) (1993). The Bombax ceiba forest in Menghan, Xishuangbanna. Acta Botanica Yunnanica (云南植物研究)，15, 191 - 195. (in Chinese with English abstract)

Li BG (李保贵), Zhu H (朱华), Wang H (王洪) (1999). The Pterocarya tonkinensis forest on the river banks of Xishuangbanna. Guihaia (广西植物) , 19, 22 - 26. (in Chinese with English abstract)

Lin MZ (林媚珍), Zhou ZD (卓正大), Guo ZH (郭志华) (1996). Some problems on the monsoon forest in Guangdong. Acta Phytoecologica Sinica (植物生态学报), 20, 90-96. (in Chinese with English abstract)

Qu ZX (曲仲湘) (1960). Nature reserves in Yunnan. Journal of Yunnan University (云南大学学报), 1, 1-4. (in Chinese)

Richards PW (1996). The Tropical Rain Forest, an Ecological Study 2nd edn. Cambridge Uinversity Press, London, 159 205.

Schmiper AFW (1903). Plant-Geography Upon a Physiological Basis. Oxford University Press, Oxford.

Wang BS (王伯荪). 1987. Discussion on the horizontal zonation of monsoon forest. Acta Phytoecologica Sinica (植物生态学报), 11, 154 - 157. (in Chinese with English abstract)

Wang BS (王伯荪), Zhang WY (张炜银) (2002). The groups and features of tropical vegetation of Hainan Island. Guihaia (广 西植物), 22, 107-115. (in Chinese with English abstract)

Wang H (王洪), Zhu H (朱华) (1990). A study on Anogeissus acuminata community. Acta Botanica Yunnanica (云南植物研 究) , 12, 67 - 74. (in Chinese with English abstract)

Whittaker RH (1970). Communities and Ecosystems. CollierMacmilla Press, London.

Wu CY (吴征镒) 1980. Vegetation of China (中国植被). Sci- 
ence Press, Beijing, $363 \sim 379$. (in Chinese)

Wu CY (吴征钑监) 1987. Vegetation of Yunnan (云南植被). Science Press, Beijing, 164 192. (in Chinese)

Zhu H (1997) Ecological and biogeographical studies on the tropical rain forest of south Yunnan, SW China with a special reference to its relation with rain forests of tropical Asia. Journal of Biogeography, 24, $647-662$.

Zhu H (2002) . Ecology and Biogeography of the Limestone Vegetation in Southern Yunnan, SW China. Yunnan Science \& Technology Press, Kunming.
Zhu H, Wang H, Li BG (1998). The structure, species composition and diversity of the limestone vegetation in Xishuangbanna, SW China. Gardens' Bulletin, Singapore, 50, 5-33.

Zhu H (朱华), Wang H (王洪), Li BG (李保贵) (1998). Research on the tropical seasonal rainforest of Xishuangbanna, South Yunnan. Guihaia (广西植物) , 18, 371 - 384. (in Chinese with English abstract)

Zhu H, Wang H, Li BG, Sirirugsa P (2003). Biogeography and floristic affinity of the Limestone flora in southern Yunnan, China. Annals of the Missouri Botanical Garden, 90, $444-465$.

责任编辑:张丽赫 